\title{
Peroxisome Biogenesis Factor PEX13 Is Required for Appressorium-Mediated Plant Infection by the Anthracnose Fungus Colletotrichum orbiculare
}

\author{
Naoki Fujihara, ${ }^{1}$ Ayumu Sakaguchi, ${ }^{1}$ Shigeyuki Tanaka, ${ }^{1}$ Satoshi Fujii, ${ }^{1}$ Gento Tsuji, ${ }^{1}$ \\ Tomonori Shiraishi, ${ }^{2}$ Richard O'Connell, ${ }^{3}$ and Yasuyuki Kubo' \\ ${ }^{1}$ Laboratory of Plant Pathology, Graduate school of Life and Environmental Sciences, Kyoto Prefectural University, Kyoto \\ 606-8522, Japan; ${ }^{2}$ Laboratory of Plant Pathology and Genetic Engineering, Faculty of Agriculture, Okayama University, \\ Okayama 700-8530, Japan; ${ }^{3}$ Department of Plant Microbe Interactions, Max Planck Institute for Plant Breeding Research, \\ Carl von Linné Weg 10 D-50829 Köln, Germany
}

Submitted 28 September 2009. Accepted 14 December 2009.

\begin{abstract}
Peroxisomes are ubiquitous organelles of eukaryotic cells that fulfill a variety of biochemical functions, including $\beta$ oxidation of fatty acids. Here, we report that an ortholog of the Saccharomyces cerevisiae peroxisome biogenesis gene $P E X 13$ is required for pathogenicity of Colletotrichum orbiculare. CoPEX13 was identified by screening random insertional mutants for deficiency in fatty acid utilization. Targeted knockout mutants of CoPEX13 were unable to utilize fatty acids as a carbon source. Expression analysis using green fluorescent protein fused to the peroxisomal targeting signals PTS1 and PTS2 revealed that the import machinery for peroxisomal matrix proteins was impaired in copex 13 mutants. Appressoria formed by the copex 13 mutants were defective in both melanization and penetration ability on host plants, had thin cell walls, and lacked peroxisomes. Moreover, the concentration of intracellular glycerol was lower in copex13 appressoria than those of the wild type. These findings indicate that fatty acid oxidation in peroxisomes is required not only for appressorium melanization but also for cell wall biogenesis and metabolic processes involved in turgor generation, all of which are essential for appressorium penetration ability.
\end{abstract}

Colletotrichum orbiculare (syn. C. lagenarium) is an ascomycete fungus that causes anthracnose disease of cucumber. Initial host penetration is mediated by a darkly melanized infection structure called an appressorium, and melanization of the appressorial cell wall was shown to be essential for appressorium function (Kubo and Furusawa 1991; Tsuji et al. 1997). Three melanin biosynthetic genes ( $P K S 1, S C D 1$, and THRl) and one regulatory gene $(C M R l)$ involved in melanin biosynthesis have been isolated and characterized (Takano et al. 1995; Kubo et al. 1996; Perpetua et al. 1996; Tsuji et al. 2000). Appressorium melanization is also required for pathogenicity in Magnaporthe grisea, the rice blast pathogen, where it was shown that melanin functions to trap osmolytes within the cell, generating the high turgor pressure necessary for mechanical penetration of the plant cuticle and cell wall (Howard et al. 1991; Wang et al. 2005).

Corresponding author: Yasuyuki Kubo; E-mail: y_kubo@kpu.ac.jp

* The $e$-Xtra logo stands for "electronic extra" and indicates that eight supplemental figures are available online. Also, Figures 2, 3, 4, 5, and 6 appear in color online.
Peroxisome biogenesis has been studied in various organisms ranging from yeast to humans. Peroxisomes are ubiquitous eukaryotic organelles that perform a wide variety of metabolic processes, including $\beta$-oxidation of fatty acids, decomposition of hydrogen peroxide by catalase, and glyoxylate metabolism (Titorenko and Rachubinski 2001, 2004). Among plant-pathogenic fungi, metabolic processes catalyzed by peroxisomal enzymes such as multifunctional $\beta$-oxidase, carnitine acetyl transferase, and isocitrate lyase were shown to be essential for appressorium function in Magnaporthe and Colletotrichum spp. (Asakura et al. 2006; Bhambra et al. 2006; Ramos-Pamplona and Naqvi 2006). Recently, it was also reported that autophagic degradation of peroxisomes is essential for infection-related morphogenesis in C. orbiculare (Asakura et al. 2009).

Currently, 32 PEX genes have been implicated in peroxisome biogenesis and their gene products are collectively called peroxins (Wanders and Waterman 2004; Heiland and Erdmann 2005). Analysis of the whole-genome sequences of 17 fungal species has revealed the distribution of peroxins among fungi and indicated that almost all peroxins identified are conserved in yeast and filamentous fungi (Kiel et al. 2006). However, the role of peroxisome biogenesis genes in fungal plant pathogens has, so far, been limited to orthologs of Saccharomyces cerevisiae PEX6, namely ClaPEX6 in C. orbiculare (Kimura et al. 2001) and MgPEX6 in M. grisea (RamosPamplona and Naqvi 2006; Wang et al. 2007). To thoroughly evaluate the role of peroxisomes in fungal pathogenesis, it is essential to functionally characterize further peroxin genes. In the present study, we aimed to identify peroxin genes required for $C$. orbiculare pathogenicity using a forward genetic screen.

Agrobacterium tumefaciens-mediated transformation (AtMT) is a powerful tool for random insertional mutagenesis in fungi which holds great potential for the discovery of novel pathogenesis-related genes in C. orbiculare (Tsuji et al. 2003; Tanaka et al. 2007). Here, we screened a collection of AtMT transformants for impaired growth ability on fatty acid medium; the mutants obtained were then tested for loss of pathogenicity on cucumber plants. Genetic analysis of one pathogenicity mutant revealed that the phenotype was caused by disruption of a gene showing significant homology to the $S$. cerevisiae peroxin gene $P E X 13$. Localization of green fluorescent protein (GFP) fused to the peroxisome targeting signals PTS1 and PTS2 showed that CoPEX13 is required for the translocation of peroxisomal matrix proteins. Cytological and physiological analysis showed that copex13-targeted knock-out mutants were defective in appres- 
sorial melanization and contained lower concentrations of the osmolyte glycerol. Our study highlights the critical role played by peroxisome metabolism in the penetration ability of $C$. or biculare through melanin biosynthesis and turgor generation.

\section{RESULTS}

Isolation of fatty acid metabolism mutants and gene cloning.

A fatty acid utilization mutant of $C$. orbiculare, Hi1622, was identified after screening 5,000 hygromycin-resistant AtMT mutants on fatty acid medium containing oleic acid as the sole carbon source. The colony morphology of mutant Hi1622 was similar to that of the wild-type $C$. orbiculare $104-\mathrm{T}$ on potato dextrose agar (PDA) medium but the mutant was unable to grow on fatty acid medium (Supplementary Fig. S1). Mutant Hi1622 was also impaired in appressorium melanization and pathogenicity on leaves of the host plant, cucumber.

Genomic DNA adjoining the T-DNA insert was isolated from Hi1622 by the thermal asymmetric interlaced polymerase chain reaction (TAIL-PCR) and the amplified products were sequenced. In a BLASTX search against the National Center for Biotechnology Information nonredundant protein database, the sequence adjacent to the T-DNA left border showed signifi- cant homology to the $S$. cerevisiae PEX13 gene. A cosmid clone, pCoPEX $13 \cos 1$, containing this region was isolated from a genomic library of $C$. orbiculare, segments containing the $S$. cerevisiae PEX13 homologous region were subcloned into pBluescript II SK+, and the deduced open reading frame (ORF) was designated CoPEX13. Based on the preferred translation initiation codon, CoPEX13 was predicted to encode a protein of 433 amino acids with three exons (51, 514, and 734 bp) and two introns (74 and 52 bp) (Supplementary Fig. S2). The introns were confirmed by sequencing cDNAs amplified by the reverse-transcription (RT)-PCR. CoPEX13 has two putative transmembrane domains and a C-terminal Src-homology 3 (SH3) domain (Fig. 1). Analysis of the T-DNA flanking sequence from mutant Hi1622 revealed that the T-DNA was inserted at a position $125 \mathrm{bp}$ downstream of the start codon of CoPEX13 (Fig. 1).

\section{Targeted disruption of CoPEX13.}

The disruption vector pCoPEX13cos1AH-2 was used for AtMT to replace the wild-type CoPEX13 gene with the hygromycin phosphotransferase $(\mathrm{hph})$ gene through double crossover homologous recombination (Supplementary Fig. S3). In all, 13 hygromycin-resistant transformants were obtained; and, of these, nine were unable to grow on fatty acid medium. In these
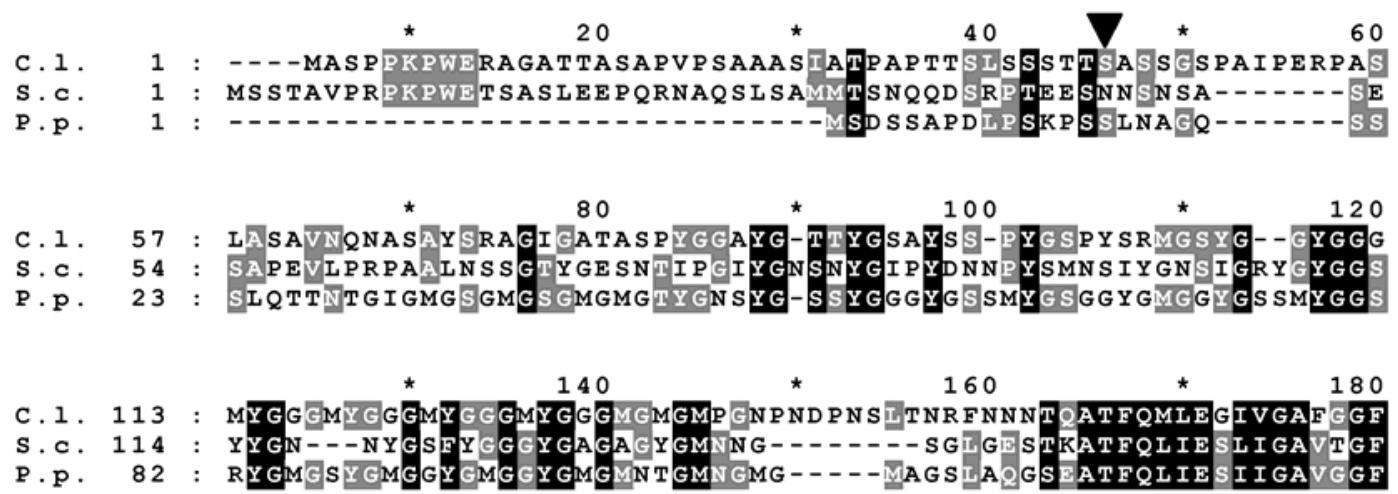

P.p. 82 : RYGMGSYGMGGYGMGGYGMGMNTGMNGMG-.- - MAGS AQGS ATFQI IESI I GAVGGE
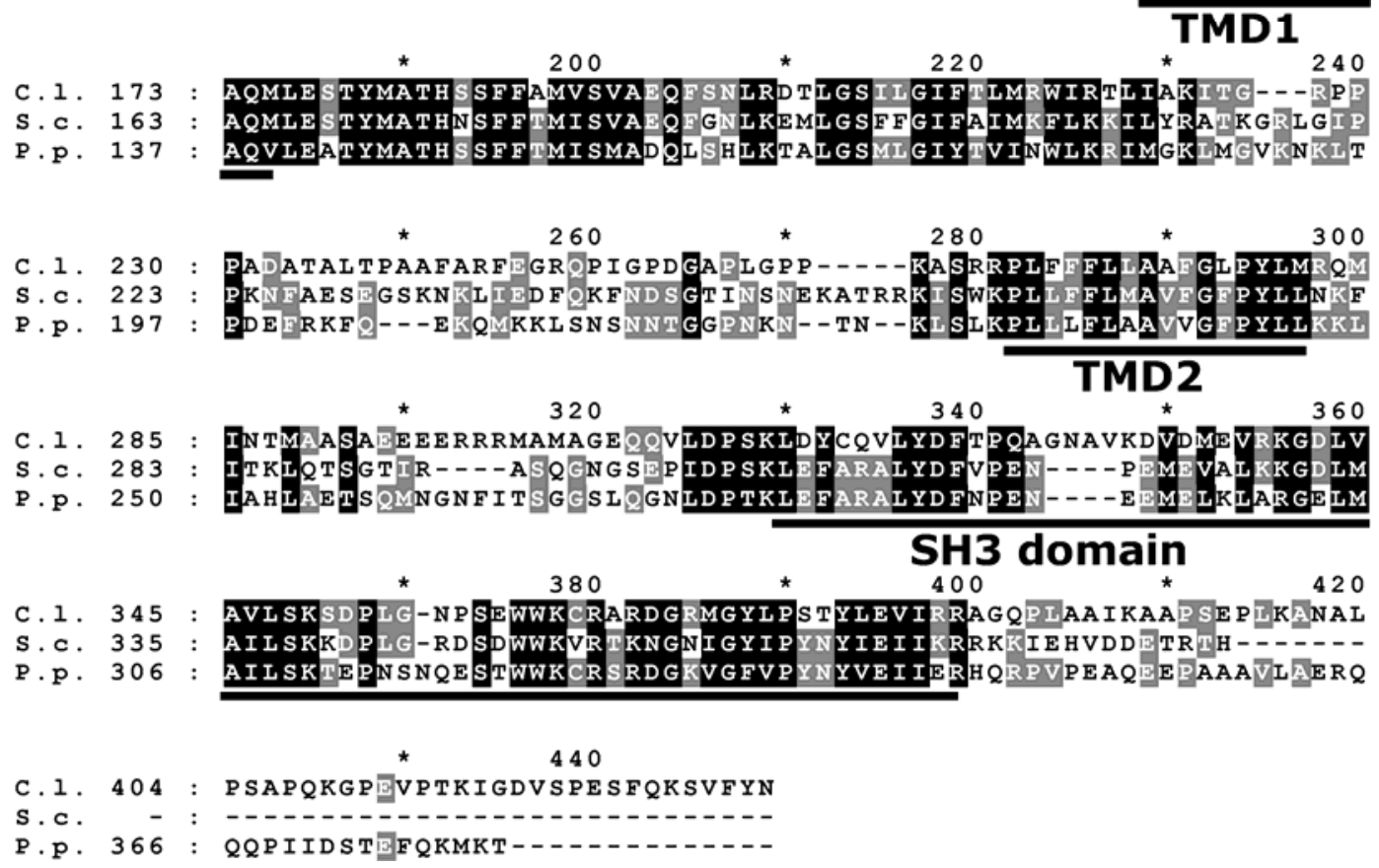

Fig. 1. Amino acid sequence alignment of Copex13p. Amino acid sequence alignment of the predicted CoPEX13 gene product with homologs from Saccharomyces cerevisiae (S.c.) and Pichia pastoris (P.p.). Similar residues are shown on a gray background. Gaps introduced for alignment are indicated by dashes. The Copex13p sequence contains two putative transmembrane domains (TMD1 and -2) and one Src-homology 3 (SH3) domain. The T-DNA insertion point in the Hi1622 mutant is indicated by an arrowhead. 
transformants, targeted gene replacement was confirmed by genomic DNA blot analysis. A single $4.3-\mathrm{kb}$ band was detected in the wild-type strain whereas a single $7.0-\mathrm{kb}$ band was detected in DPE13-1, DPE13-2, DPE13-3, and DPE13-4, as expected from a targeted gene replacement event. In ectopic transformants DPE13-E1 and E2, the 4.3-kb band and several additional bands were detected, indicative of ectopic insertion events.

\section{CoPEX13 is required}

\section{for appressorium-mediated plant infection.}

Although the growth of copex13 disruption mutants on PDA was similar to the wild type, they grew very poorly on fatty acid medium (Fig. 2A). In vitro, the copex13 disruption mutants formed spherical appressoria similar to those of the wild type but these were completely nonmelanized (Fig. 2B). Interestingly, however, the vegetative mycelia of the mutants were melanized as darkly as the wild type (Fig. 2A). On the host plant, conidia of copex 13 mutants also formed nonmelanized appressoria which very rarely penetrated host epidermal cells. In contrast, conidia of the wild type 104-T formed darkly melanized appressoria on the host plant which penetrated with high frequency to form intracellular infection hyphae (Fig. 2B). To investigate whether the pathogenicity defect shown by copex 13 mutants could be complemented by reintroduction of a wild-type copy of $C o P E X 13$, we transformed the mutant with plasmid pPEX13com1. Complementation fully restored the ability to grow on fatty acid medium, appressorium melanization, and pathogenicity on cucumber leaves. Thus, the complemented strains penetrated host epidermal cells and produced disease lesions similar to those of the wild type (Fig. 2C). The invasive growth ability of the copex 13 mutants was assessed by inoculating conidia onto wounded cucumber cotyledons.

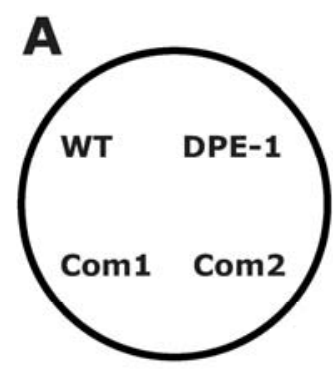

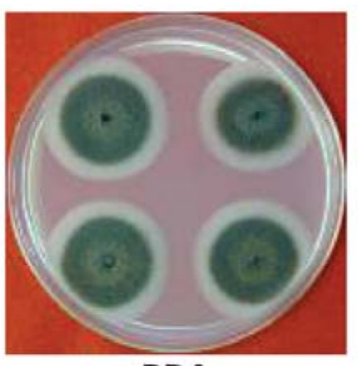

PDA

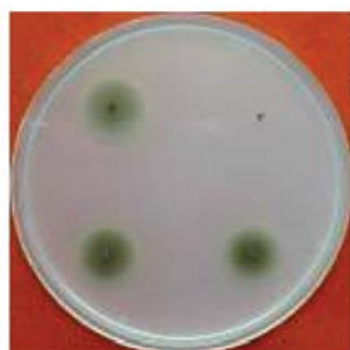

Fatty acid medium

\section{B}

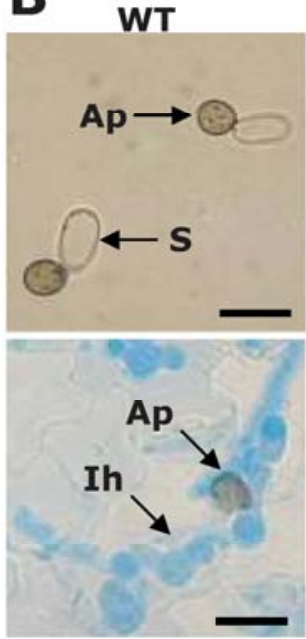

DPE13-1
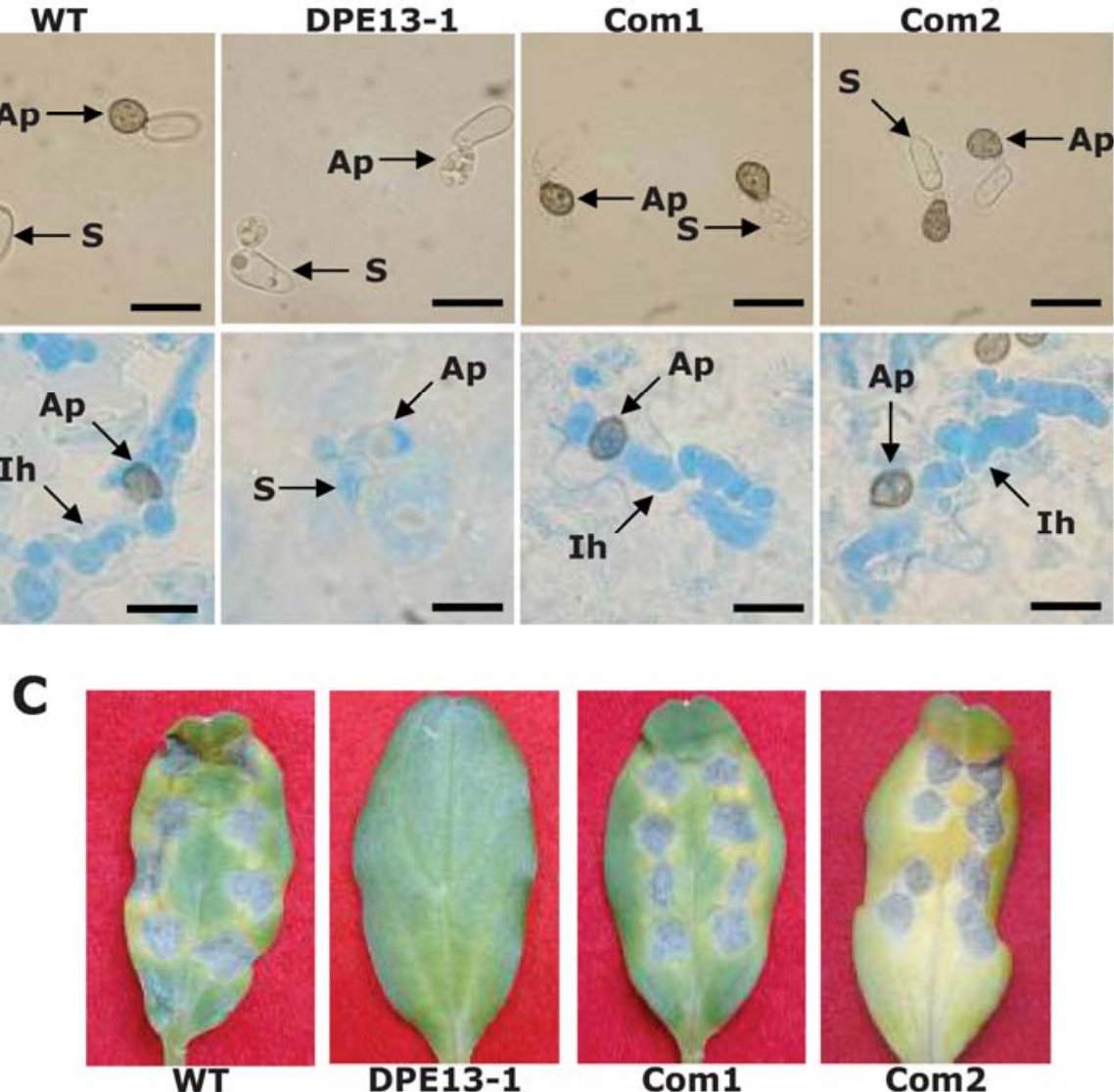

DPE13-1

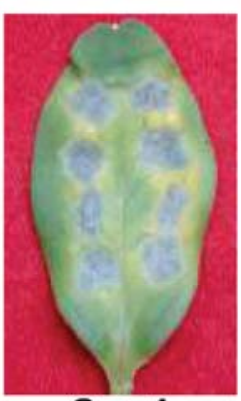

Com1

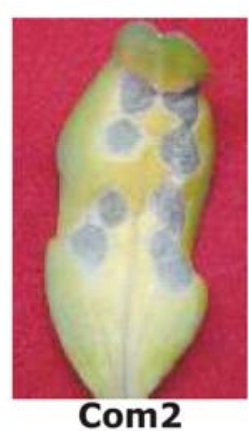

Fig. 2. Phenotypic analysis of the copex13 mutant and complemented strains. A, Seven-day-old culture of the Colletotrichum orbiculare wild-type strain 104-T (WT), copex13 mutant strain DPE13-1, and complemented transformants Com1 and Com2 on potato dextrose agar (PDA) and fatty acid medium. B, Appressorium formation on glass slides and infection assay on cucumber cotyledons. Upper panel: conidia were germinated on glass slides at $24^{\circ} \mathrm{C}$ for $24 \mathrm{~h}$. Lower panel: conidia were inoculated on excised cucumber cotyledons, incubated for 3 days, stained with lactophenol-Aniline blue, and viewed by light microscopy. Ap, appressorium; S, spore; Ih, infection hyphae inside host epidermal cell. C, Symptoms produced on cucumber cotyledons 3 days after inoculation with the WT, copex13 mutant DPE13-1, and complemented transformants Com1 and Com2. 
The copex13 mutants formed lesions similar to the wild type around wound sites at 7 days after inoculation (Supplementary Fig. S4), indicating that CoPEX13 is not essential for invasive growth in the host plant.

Next, to assess whether the penetration defect shown by appressoria of the copex 13 mutants resulted from the absence of cell wall melanin, we restored melanization by the addition of scytalone, an intermediate in the melanin biosynthesis pathway (Kubo et al. 1996). Appressorial penetration ability was assayed on artificial cellulose membranes. In the case of the $C$. orbiculare albino mutant $p k s l$, affected in a polyketide synthaseencoding gene (Takano et al. 1995), exogenous scytalone restored appressorial melanization and the ability to penetrate into cellulose membranes (Fig. 3). However, addition of scytalone failed to restore the penetration ability of copex 13 (Table 1 ), even though the treated appressoria became melanized. Previously, it was shown that the appressorial melanization defect of $C$. orbiculare pex6 mutants was partially restored by the addition of glucose (Kimura et al. 2001). In contrast, melanization was not affected by glucose in copex 13 mutants (data not shown). Furthermore, although appressoria of $C$. orbiculare pex6 mutants retained the ability to form penetration hyphae inside cellulose membranes (Kimura et al. 2001), the copex13 mutant was almost completely defective in penetration of these membranes. These findings suggest that the host penetration defect shown by copex 13 mutant appressoria is caused not only by their failure to melanize but also by impairment of some other cellular functions.

\section{Peroxisome abnormalities in copex 13 mutants.}

Pex13p of $S$. cerevisiae is an integral peroxisomal membrane protein possessing a cytosolically exposed C-terminal SH3 domain which is involved in protein-protein interactions and mediates assembly of specific protein complexes. Thus, the SH3 domain was shown to interact with Pex5p and Pex14p, and yeast pex13 mutants show defects in both PTS1 and PTS2 protein import (Elgersma et al. 1996; Erdmann and Blobel 1996; Gould et al. 1996). To test whether GFP was correctly targeted to peroxisomes in the $C$. orbiculare pex 13 mutant, the PTS1 and PTS2 signals were fused to the C-terminus and Nterminus of GFP (eGFP), respectively (Supplementary Figs. S5 and S6). Plasmids pEGFPPTS1 and pPTS2EGFP containing GFP-PTS1 and PTS2-GFP, respectively, were transformed into the wild-type strain and the copex 13 mutant DPE13-1. Plasmid pBI-G3eGFP was also used to generate transformants expressing GFP in the cytosol.

The growth phenotypes of strains expressing GFP-PTS1, PTS2-GFP, and cytosolic GFP were indistinguishable from those of the parental strains (data not shown). In the $C$. orbiculare wild-type strain expressing GFP-PTS1, the marker proteins showed a punctate pattern of fluorescent labeling in vegetative hyphae (Fig. 4) and conidia (Fig. 5), indicating that GFP-PTS1 is correctly recognized and transported into peroxisomes. In the copex 13 mutant, GFP-PTS1 showed a diffuse fluorescence dis- tributed throughout the cytoplasm, similar to cytosolic GFP expression in the wild type (Figs. 4 and 5). Likewise, PTS2-GFP expressed in the wild-type strain also showed a punctate fluorescence pattern, suggesting that correct targeting into peroxisomes had occurred (Figs. 4 and 5). In contrast, PTS2-GFP was not localized in peroxisomes in the copex 13 mutant (Figs. 4 and 5). These results indicate that the organelles labeled by GFP-PTS1 and PTS2-GFP represent peroxisomes and that copex 13 mutants are defective in the import of peroxisome matrix proteins possessing either PTS1 or PTS2 targeting signals.

Next, to investigate whether lipid body dynamics were altered in copex 13 mutants, we used Nile Red as a fluorescent probe to label lipids for microscopy (Weber et al. 2001). Wild-type appressoria have darkly melanized cell walls which interfere

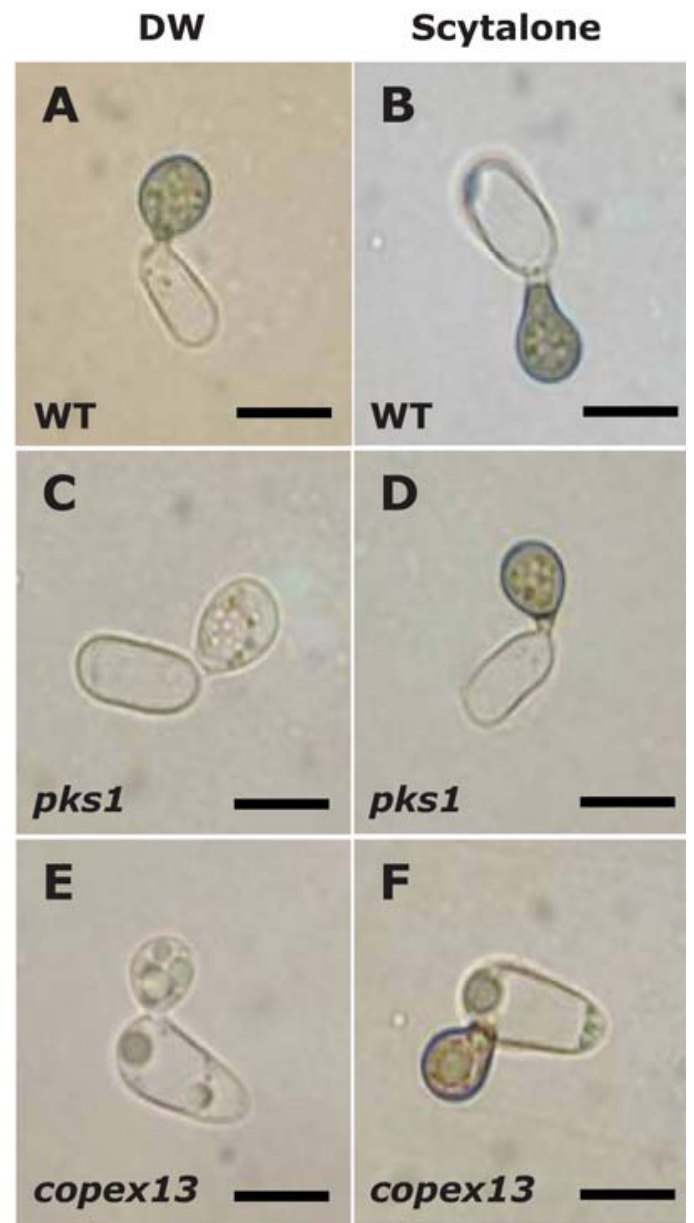

Fig. 3. copex13 Mutant strains are defective in appressorium melanization. Conidial suspension of $\mathbf{A}$ and $\mathbf{B}$, the Colletotrichum orbiculare wild-type strain; $\mathbf{C}$ and $\mathbf{D}$, the pks 1 mutant; and $\mathbf{E}$ and $\mathbf{F}$, the copex 13 mutant were spotted onto glass slides and incubated at $24^{\circ} \mathrm{C}$ for $24 \mathrm{~h}$ in distilled water (left panels) or in $1 \mathrm{mM}$ scytalone (right panels). Bar $=10 \mu \mathrm{m}$.

Table 1. Conidial germination and appressorial function in copex13 mutants

\begin{tabular}{|c|c|c|c|c|}
\hline Strains & Conidial germination $^{a}$ & Appressorium formation & Melanized appressoria & Penetration into cellulose membrane \\
\hline \multicolumn{5}{|l|}{ Distilled water } \\
\hline 104-T (wild-type) & $94.5 \pm 2.1$ & $97.9 \pm 0.8$ & $99.2 \pm 1.2$ & $97.2 \pm 1.5$ \\
\hline pks1 mutant & $92.8 \pm 2.0$ & $95.0 \pm 2.3$ & 0 & $7.4 \pm 3.4$ \\
\hline copex 13 mutant & $94.6 \pm 3.0$ & $99.5 \pm 0.4$ & 0 & $0.6 \pm 0.4$ \\
\hline \multicolumn{5}{|l|}{ Scytalone } \\
\hline 104-T (wild-type) & $96.3 \pm 1.0$ & $97.2 \pm 0.9$ & $99.6 \pm 0.2$ & $98.9 \pm 0.5$ \\
\hline pks 1 mutant & $91.4 \pm 1.6$ & $96.8 \pm 1.0$ & $99.0 \pm 0.5$ & $97.3 \pm 0.5$ \\
\hline copex 13 mutant & $95.5 \pm 0.2$ & $99.2 \pm 0.6$ & $99.3 \pm 0.5$ & $0.3 \pm 0.2$ \\
\hline
\end{tabular}

${ }^{a}$ Percentage of conidial germination, appressorium formation, melanized appressoria, or penetration into cellulose membrane was counted at $24 \mathrm{~h}$ after incubation at $24^{\circ} \mathrm{C}$. Approximately 100 conidia were observed in each sample and each experiment was repeated at least three times. 
with microscopic observation of fluorescent-labeled lipid bodies. Therefore, we used the $p k s 1$ albino mutant to study lipid body dynamics. Lipid droplets appeared larger in appressoria of the copex 13 mutant than in those of the pksl mutant after Nile Red staining (Fig. 6). These results suggest that mutation of the peroxisome biogenesis gene CoPEX13 affects the mobilization of stored lipid reserves during appressorium formation and maturation, which may be related to a deficiency in fatty acid metabolism. Furthermore, we tested the tolerance of the copex 13 mutant to hydrogen peroxide as an oxidative stress. Compared with the wild-type strain, the mutant showed higher sensitivity to hydrogen peroxide $(2.5 \mathrm{mM})$ on PDA medium, suggesting that peroxisomal proteins such as catalase may contribute to oxidative stress tolerance (Supplementary Fig. S7).

\section{Ultrastructural defects in the copex 13 mutant.}

Ungerminated conidia of the copex 13 mutant appeared identical in ultrastructure to those of wild-type $C$. orbiculare, and the cytoplasm of both was dominated by abundant lipid bodies (Fig. 7A and B). At 3 days after inoculation on cucumber cotyledons, wild-type spores had germinated to form fully mature, melanized appressoria, which had thick cell walls (approximately $100 \mathrm{~nm}$ ) comprising a highly electron-opaque melanin layer adjoining the plasma membrane, an electron-lucent mid-

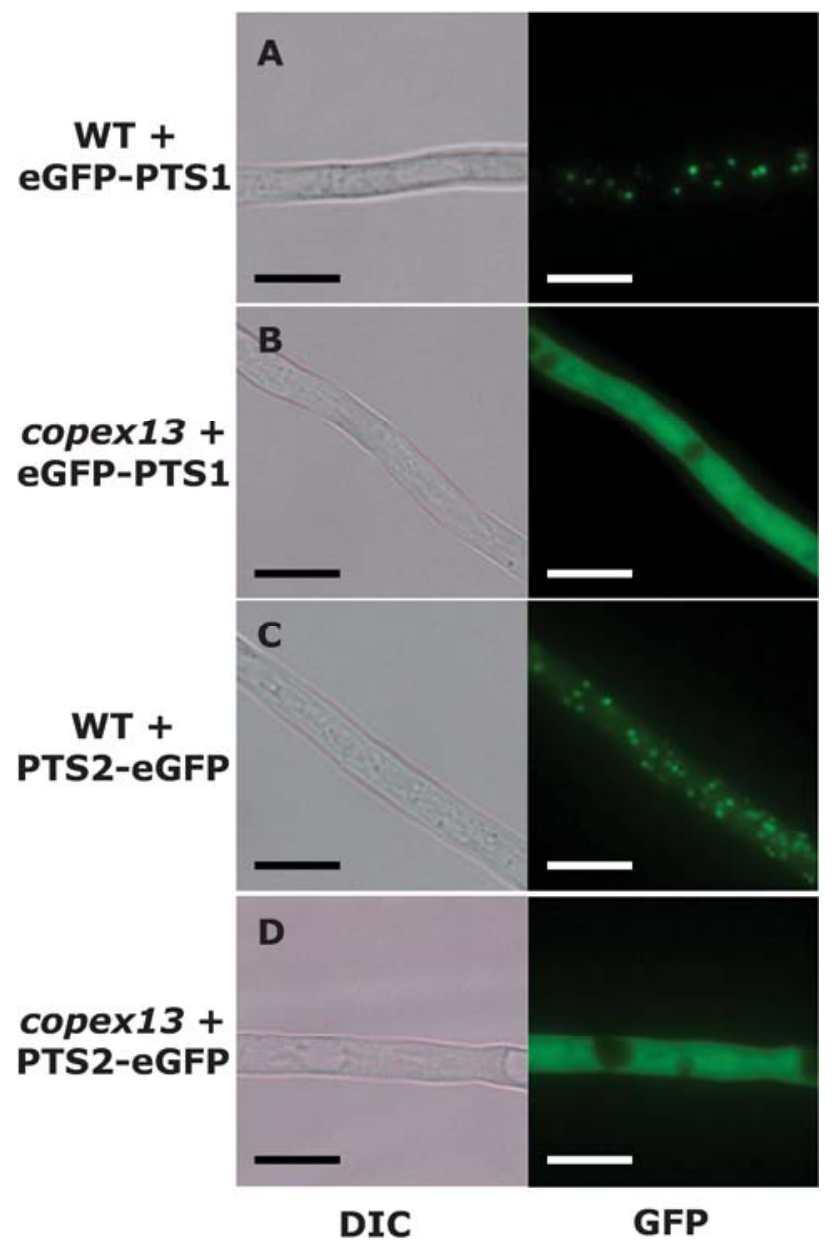

Fig. 4. Mislocalization of green fluorescent protein (GFP)-PTS1 and GFPPTS2 proteins in vegetative hyphae of the copex13 mutant. A, The Colletotrichum orbiculare wild-type strain (WT) expressing GFP-PTS1; B, the copex13 expressing GFP-PTS1; C, the WT expressing GFP-PTS2; and D, the copex13 expressing GFP-PTS2 were all grown for 3 days on SD minimal agar medium $(0.67 \%$ [wt/vol] yeast nitrogen base without amino acids, $2 \%$ [wt/vol] glucose, and $2 \%$ [wt/vol] agar). The localization of GFP-PTS1 and GFP-PTS2 proteins in growing vegetative hyphae was observed by epifluorescence microscopy. $\mathrm{Bar}=10 \mathrm{~nm}$. dle layer, and an electron-opaque outer layer (Fig. 7C and D). At this stage, appressoria contained a basal penetration pore and were starting to penetrate the plant cuticle and cell wall. Their cytoplasm contained numerous peroxisomes with prominent electron-opaque inclusions (Fig. 7C and G), which displayed a lattice-like crystalline structure at high magnification (Fig. $7 \mathrm{H}$ ). Crystalline protein cores are a characteristic feature of peroxisomes in many other organisms (Veenhuis et al. 1979; Heinze et al. 2000; Kim et al. 2004). In C. orbiculare appressoria, peroxisomes were frequently located around the periphery of lipid bodies, the surface of which appeared in contact with the peroxisomal membrane (Fig. 7G). In contrast, the appressorium-like structures formed by the copex 13 mutant contained no visible peroxisomes, and lipid bodies were more abundant than in wild-type appressoria (Fig. 7E). Moreover,

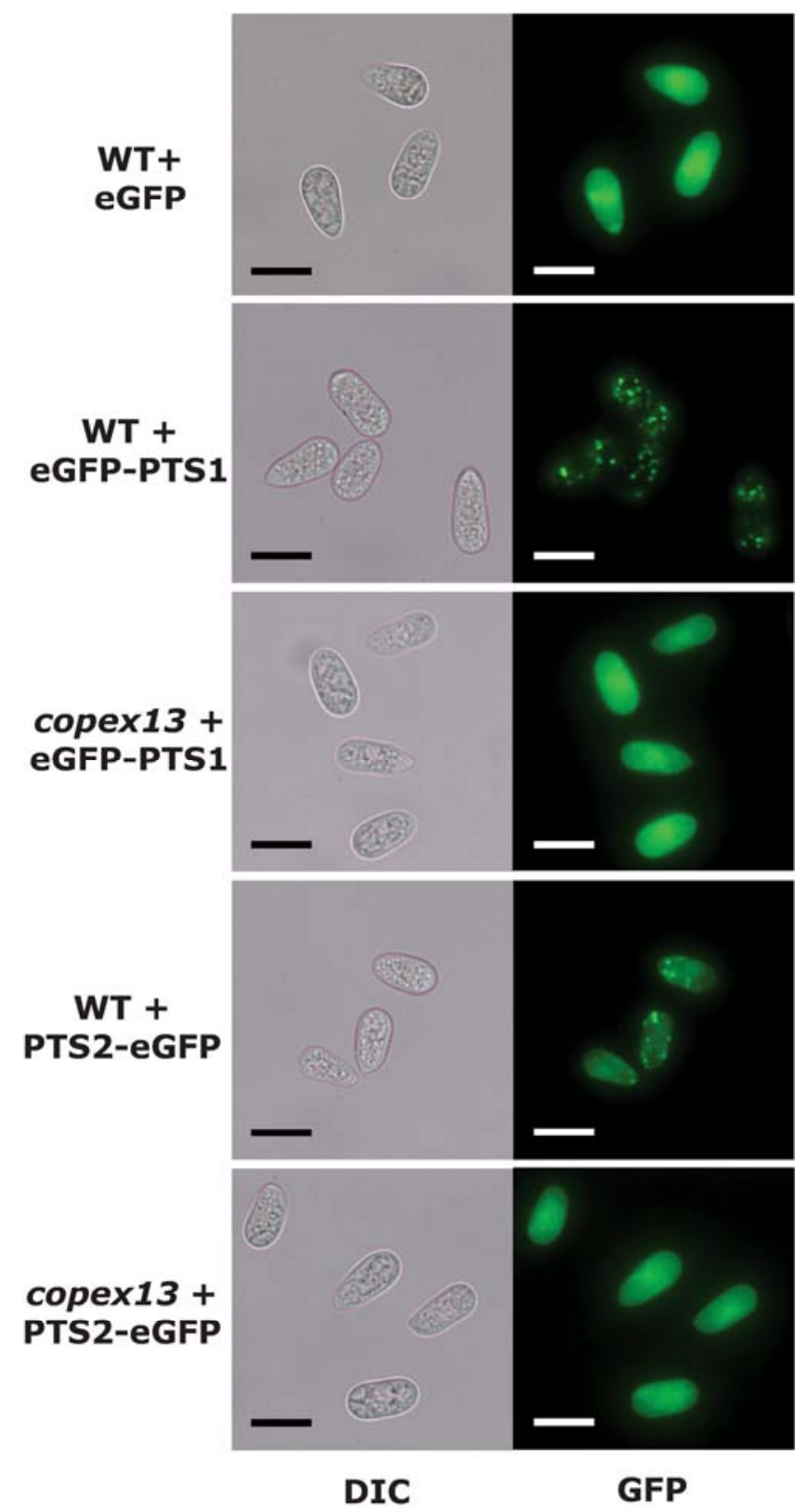

Fig. 5. Mislocalization of green fluorescent protein (GFP)-PTS1 and GFPPTS2 proteins in conidia of the copex13 mutant. Ungerminated conidia of the Colletotrichum orbiculare wild-type strain (WT) and copex13 mutant expressing GFP-PTS1 and GFP-PTS2 fusion proteins were harvested from colonies in distilled water, mounted on glass slides, and observed by differential interference contrast microscopy (left panels) and epifluorescence microscopy (right panels). Bar $=10 \mu \mathrm{m}$. 
copex13 appressoria had thinner cell walls than the wild type (approximately $45 \mathrm{~nm}$ ), comprising a single electron-lucent layer with no detectable melanin (Fig. 7F).

\section{Appressoria of the copex13 mutant are impaired in osmolyte accumulation.}

To evaluate whether the penetration defect shown by appressoria of the copex 13 mutant is associated with a reduction in appressorial turgor, we assayed the glycerol content of extracts prepared from appressoria formed on glass slides (Fig. 8). After incubation for $8 \mathrm{~h}$, when appressoria were starting to develop, the $C$. orbiculare wild-type had accumulated a slightly higher concentration of glycerol than both pks1 and pex 13 mutants. After incubation for $16 \mathrm{~h}$, when appressoria were fully melanized and mature, the accumulation of glycerol by the $p k s l$ and pex13 mutants was significantly lower than in the wild type. This result suggests that the penetration defect shown by appressoria of the copex 13 mutant is at least partly related to reduced turgor generation, resulting from impaired accumulation of osmolytes within the cell.

\section{DISCUSSION}

Previously, the only peroxisome biogenesis genes to be studied in relation to fungal pathogenicity were orthologs of PEX6 in M. grisea and C. orbiculare (Kimura et al. 2001; Ramos-Pamplona and Naqvi 2006; Wang et al. 2007). In the present study, a targeted screen for mutants defective in fatty acid metabolism revealed that a PEX13 ortholog is also required for pathogenicity in $C$. orbiculare. We show that appressoria of the pex13 mutant are defective in melanization, cell wall formation, and glycerol accumulation, underlining the critical role played by peroxisome metabolism in the ability of C. orbiculare to penetrate host cells.

In humans and yeast, $P E X 13$ genes were shown to encode an essential component of the peroxisomal protein import machinery (Ergersma et al. 1996; Erdmann and Blobel 1996; Gould et al. 1996). Peroxisomal matrix proteins are directed to the peroxisome lumen by the presence of either a PTS1 or PTS2 targeting signal. The majority of matrix proteins possess a PTS1 signal, comprising the tripeptide SKL, or similar variants, located at the extreme carboxy terminus of the protein (Subramani 1993). PTS2 targeting signals are located close to the amino terminus and have the consensus sequence H/R-L$\mathrm{X}_{5}$-H-L (Swinkels et al. 1991; Subramani et al. 2000). PTS1 and PTS2 signals are recognized by the import receptors Pex 5p and Pex $7 p$, respectively, and, after receptor binding, the matrix proteins are transferred across the peroxisomal membrane. The core components of the peroxisomal docking complex for the PTS receptors, Pex13p and Pex14p, are required for translocation of proteins across the peroxisome membrane. Pex $13 p$ is an integral membrane protein characterized by an N-terminal domain, which is orientated toward the cytosol and binds to the PTS2 receptor Pex7p (Girzalsky et al. 1999; Stein et al. 2002), and a C-terminal SH3 domain, which is also exposed to the cytosol and provides a binding site for Pex $5 p$ and Pex14p. Thus, Pex13p is concerned with the import of proteins carrying both PTS1 and PTS2 signals (Erdmann and Blobel 1996; Gould et al. 1996; Albertini et al. 1997; Barnett et al. 2000) (Supplementary Fig. S8). The SH3 domain is conserved across highly divergent taxonomic groups, from humans to yeast, indicating that the protein import machinery is shared by most eukaryotes and that the CoPEX13 is likely to perform similar functions as in other organisms.

The most well-characterized PTS2 protein is 3-ketoacyl-CoA thiolase, a fatty acid $\beta$-oxidation enzyme found in yeasts, animals, and plants. Here, we constructed a PTS2-GFP fusion protein, composed of the $17 \mathrm{~N}$-terminal amino acids of the $S$. cerevisiae 3-ketoacyl-CoA thiolase, Fox3p, fused to GFP. PTS2GFP was localized to peroxisomes in the $C$. orbiculare wildtype, which is the first report of the localization of a PTS2 signal protein to peroxisomes in a plant-pathogenic filamentous fungus. Similarly, GFP-PTS1 was localized to peroxisomes in the wild type. In contrast, analysis of transformants expressing GFP-PTS1 and PTS2-GFP fusion proteins indicated that matrix proteins carrying either of these targeting signals were not imported into peroxisomes of the copex 13 mutant. This is consistent with reports that neither type of matrix proteins are imported into peroxisomes of the $S$. cerevisiae pex 13 null mutant (Elgersma et al. 1996; Erdmann and Blobel 1996; Gould et al. 1996). Similarly, the Aspergillus nidulans pex13 mutant fails to import malate synthase and isocitrate lyase into peroxisomes via the PTS1 and PTS2 receptors, respectively (Hynes et al. 2008).

\section{The role of peroxisome metabolism}

in appressorium-mediated plant infection.

In $C$. orbiculare, melanin is synthesized through the pentaketide pathway, in which 1,3,6,8-tetrahydroxynaphthalene (T4HN) is synthesized by polyketide synthase from malonylCoA derived from acetyl-CoA (Fujii et al. 2000). It is likely that energy and substrates required for the infection process are derived from the metabolism of storage materials in the spore, because the conidia of many plant-pathogenic fungi germinate to form infection structures in the absence of exogenous nutrients. Appressoria formed by copex 13 mutants were deficient in appressorial melanization and penetration ability but melanization could be restored by the addition of exogenous scytalone. This finding is consistent with melanin biosynthesis in appressoria depending mainly on acetyl-CoA produced by the $\beta$-oxidation of fatty acids in peroxisomes (Kimura et al. 2001). However, scytalone treatment did not restore the ability of copex 13 appressoria to penetrate cellophane, indicating that the lack of cell wall melanin is not the only factor causing impaired penetration. The pronounced enlargement of lipid droplets in appressoria of the copex 13 mutant suggests that the defect in peroxisome function not only prevents melanin biosynthesis in appressoria but also the mobilization of storage lipids. Both Nile red labeling and transmission electron microscopy (TEM) showed that lipid bodies persisted in ap-

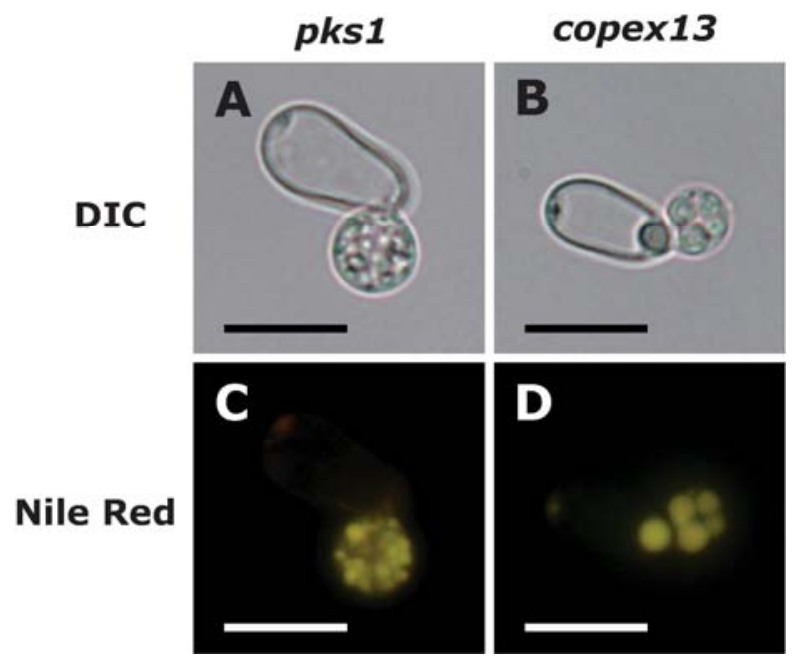

Fig. 6. Distribution of lipid droplets in appressoria of the copex13 mutant. Appressoria of the $\mathbf{A}$ and $\mathbf{C}$, Colletotrichum orbiculare pks 1 mutant and $\mathbf{B}$ and D, copex 13 mutant were formed on glass slides after $24 \mathrm{~h}$ of incubation at $24^{\circ} \mathrm{C}$. Cells were stained with Nile Red to detect lipids and viewed with differential interference microscopy (upper panels) and epifluorescence microscopy (lower panels). Bar $=10 \mu \mathrm{m}$. 
pressoria of the copex 13 mutant at a developmental stage when these organelles were largely depleted from wild-type appressoria. Lipid mobilization in the appressoria of $M$. grisea and $C$. gloeosporioides has been reported to occur through a process resembling microautophagy, involving internalization of lipid bodies into the central vacuole (Schadeck et al. 1998; Thines et al. 2000; Weber et al. 2001). However, we found no ultrastructural evidence for this process in wild-type appressoria of $C$. orbiculare, suggesting that the machinery for lipid mobilization may differ between these appressorium-forming fungi. In C. orbiculare, lipid bodies were encircled by peroxisomes and made intimate contact with the peroxisomal membrane. A similar close association between these organelles was reported in germinating spores of $C$. truncatum (Van Dyke and Mims 1991), oleic acid-cultured yeast cells (Binns et al. 2006), and hyphae of Botryosphaeria spp. (Kim et al. 2004). This close physical proximity raises the possibility of a metabolic link, where fatty acids derived from lipolysis in lipid bodies may be directly transferred across the bounding membranes into peroxisomes for $\beta$-oxidation (Binns et al. 2006). There is also evidence that peroxisomal contact can stimulate lipid breakdown within lipid bodies (Binns et al. 2006).

Peroxisome functions include the glyoxylate cycle, and most of the enzymes involved in this pathway are located in peroxisomes (Titorenko and Rachubinski 2001, 2004). It was shown that the glyoxylate cycle is important for the temporal regulation of pathogenesis in both M. grisea and C. orbiculare, and $M$. grisea mutants affected in the icl gene, encoding isocitrate lyase, were defective in turgor generation (Wang et al. 2003; Asakura et al. 2006). Wang and associates (2007) also showed
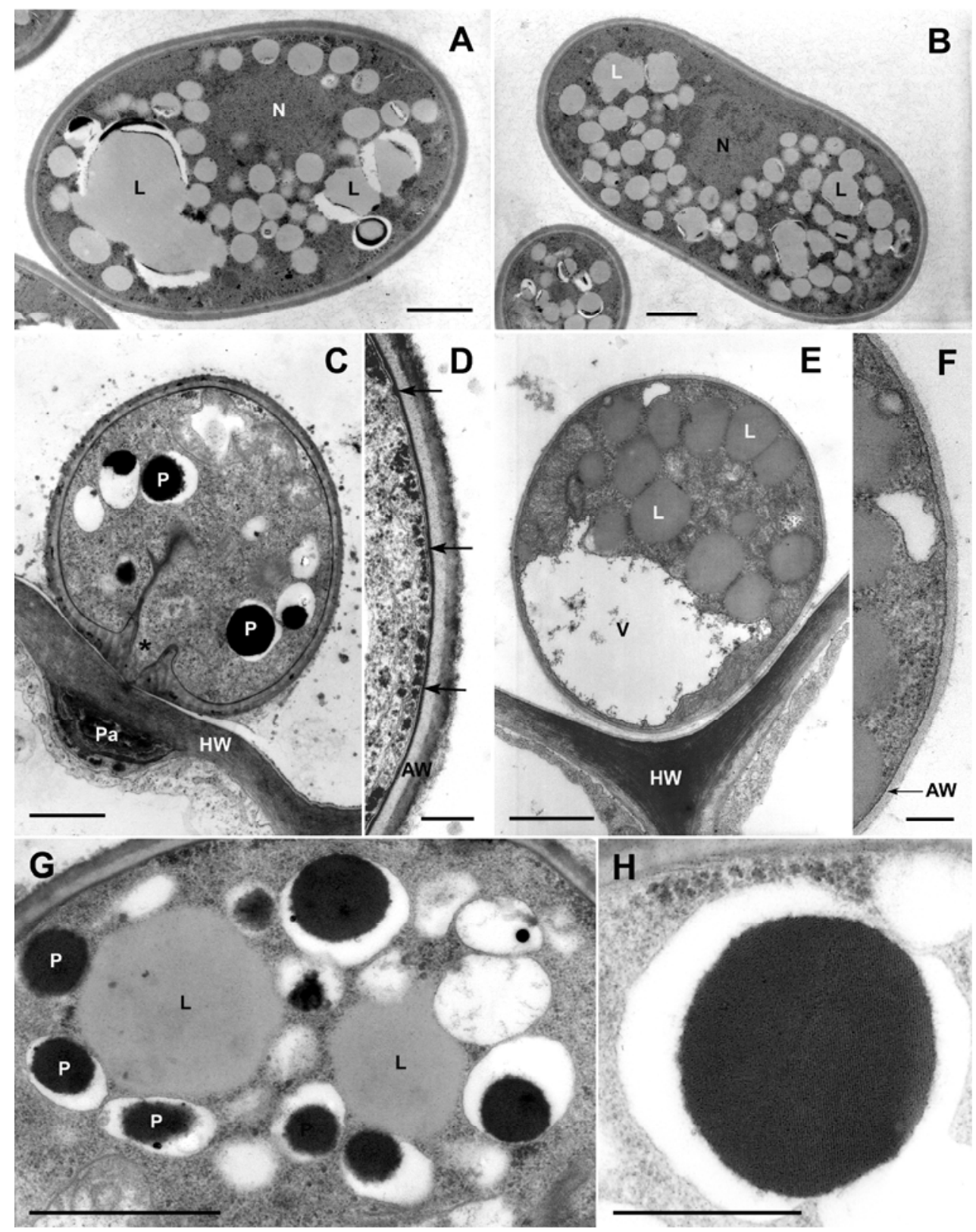

Fig. 7. Ultrastructure of the copex 13 mutant. Transmission electron micrographs showing ungerminated conidia of A, wild-type Colletotrichum orbiculare and $\mathbf{B}$, mutant copex13. Each spore contains a single nucleus $(\mathrm{N})$ and many lipid bodies $(\mathrm{L})$. $\mathbf{C}-\mathbf{H}$, Transmission electron micrographs showing $C$. orbiculare appressoria formed on cucumber cotyledons at 3 days after inoculation. C, Wild-type appressorium has a thick cell wall and contains many peroxisomes (P). D, Wild-type appressorial wall (AW) showing electron-opaque melanin layer (arrows) adjoining the plasma membrane. Bar $=0.2 \mu \mathrm{m}$. E, copex13 Mutant appressorium contains many lipid bodies (L) but no peroxisomes. F, Appressorial wall (AW) of the copex13 mutant is thin, single layered, and electron lucent. Bar $=0.2 \mu \mathrm{m}$. G, Lipid bodies in a wild-type appressorium are surrounded by peroxisomes $(\mathrm{P})$ with electron-opaque protein cores. $\mathbf{H}$, Peroxisome protein cores have a crystalline structure. $\mathrm{Bar}=0.5 \mu \mathrm{m} . \mathrm{HW}=$ host wall; $\mathrm{Pa}=$ papilla; asterisk = penetration pore; $\mathrm{V}=$ vacuole. Unless otherwise stated, all scale bars $=1 \mu \mathrm{m}$. 
that a multifunctional $\beta$-oxidation enzyme is essential for pathogenesis in $M$. grisea. TEM revealed that appressorial cell walls of the copex 13 mutant not only lacked melanin but were also much thinner than those of the wild type and were not differentiated into multiple layers. This suggests that peroxisome function is required for cell wall biogenesis during appressorium formation. AcetylCoA derived from peroxisomal $\beta$-oxidation of fatty acids is a substrate for the glyoxylate cycle and gluconeogenic pathway, which contribute to the synthesis of cell wall polymers such as chitin and glucan (Thines et al. 2000; Wang et al. 2003; Ramos-Pamplona and Naqvi 2006). Therefore, peroxin mutants are likely to display cell wall defects due to their inability to import enzymes of the glyoxylate cycle into peroxisomes (Bhambra et al. 2006).

In conclusion, it is likely that defects in melanization, cell wall synthesis, and turgor generation all contribute to the lack of host penetration ability shown by appressoria of the $C$. orbiculare pex 13 mutant.

\section{MATERIALS AND METHODS}

\section{Fungal and bacterial strains.}

C. orbiculare (Berk. \& Mont.) Arx (syn. C. lagenarium (Pass.) Ellis \& Halst.) 104-T (MAFF240422) was used as the wild-type strain. All $C$. orbiculare cultures were maintained on PDA medium (3.9\% [wt/vol]) (Difco Laboratories, Detroit) at $24^{\circ} \mathrm{C}$ in the dark. Fatty acid medium contained $1.6 \%$ (wt/vol) yeast nitrogen base without amino acids (Difco Laboratories), $1 \%$ (wt/vol) $\mathrm{NH}_{4} \mathrm{NO}_{3}, 0.5 \%$ (vol/vol) Tween 80, and $2.0 \%$ (wt/vol) agar. $\mathrm{pH}$ was adjusted to 6.0 with $\mathrm{Na}_{2} \mathrm{HPO}_{4}$. The $C$. orbiculare strains introduced with GFP-PTS1 or GFP-PTS2 were grown on SD minimal agar medium $(0.67 \%$ [wt/vol] yeast nitrogen base without amino acids, $2 \%$ [wt/vol] glucose, and 2\% [wt/vol] agar). Escherichia coli DH5- $\alpha$ and Agrobacterium tumefaciens strains C58C1 and LBA4404 were used for transformation of $C$. orbiculare by AtMT. E. coli was cultured in Luria-Bertani broth at $37^{\circ} \mathrm{C}$. The medium was supplemented when necessary with ampicillin at $50 \mu \mathrm{g} / \mathrm{ml}$ or kanamycin at $50 \mu \mathrm{g} / \mathrm{ml}$, or both. A. tumefaciens was cultured in AB minimal medium (Lichtenstein and Draper 1986) at $24^{\circ} \mathrm{C}$. The medium was supplemented when necessary with kanamycin at $50 \mu \mathrm{g} / \mathrm{ml}$ and rifampicin at $100 \mu \mathrm{g} / \mathrm{ml}$.

\section{Fungal transformation.}

For AtMT, $C$. orbiculare was transformed as described previously (Tsuji et al. 2003). A. tumefaciens C58C1 carrying the binary vector $\mathrm{pBIG} 2 \mathrm{RHPH} 2$ was grown in $\mathrm{AB}$ minimal medium (Lichtenstein and Draper 1986). The bacterial culture was diluted with induction medium (IM) (Bundock et al. 1995) to an optical density at $660 \mathrm{~nm}$ of 0.1 to 0.2 . Fungal conidia were mixed with the diluted bacteria to a final concentration of $10^{6}$ to $10^{7}$ conidia/ml. The mixture $(100 \mu \mathrm{l})$ was spread over a filter paper (hardened low ash grade 50) (Whatman, Maidstone, U.K.) on an IM plate containing $50 \mu \mathrm{M}$ acetosyringone (AS) (SigmaAldrich Japan, Tokyo). After incubation at $21^{\circ} \mathrm{C}$ for 2 days, the filters were transferred to PDA medium containing hygromycin $\mathrm{B}$ at $100 \mu \mathrm{g} / \mathrm{ml}$ (Wako Chemicals, Osaka, Japan), cefotaxim at $50 \mu \mathrm{g} / \mathrm{ml}$ (Wako Chemicals), and spectinomycin at $50 \mu \mathrm{g} / \mathrm{ml}$ (Wako Chemicals). Bialaphos-resistant transformants were selected on SD medium containing bialaphos at $10 \mu \mathrm{g} / \mathrm{ml}$ (Meiji Seika Kaisha, Ltd., Tokyo), cefotaxim at $50 \mu \mathrm{g} / \mathrm{ml}$, and spectinomycin at $50 \mu \mathrm{g} / \mathrm{ml}$.

\section{Cloning and sequencing.}

The TAIL-PCR protocol was used to clone genomic DNA fragments flanking the T-DNA insert from fungal transformants (Liu et al. 1995), and the flanking sequences were analyzed as described by Tsuji and associates (2003). Amplified PCR products were analyzed by agarose gel electrophoresis and sequenced with the Big-Dye terminator cycle sequencing ready reaction kit (Applied Biosystems Japan, Tokyo) and an ABI PRISM 310 automated DNA sequencer (Applied Biosystems Japan). A cosmid clone pCoPEX13cos 1 of CoPEX13 was selected from a cosmid library of $C$. orbiculare 104-T by PCR using primer pair PEX13S (5'-GCGGATCCATGGCATCGCCG CCAAAG-3') and PEX13AS (5'-GCGAATTCCTAAGTAGTT ACCCGCCAGGCC-3') designed from the obtained DNA sequence. To obtain the entire CoPEX13 ORF, the EZ::TN <KAN$2>$ Insertion Kit (Epicenter, Madison, WI, U.S.A.) was used to insert a transposon containing a selection marker into the target DNA. Clones containing the $<\mathrm{KAN}-2>$ transposon was sequenced using primers KAN2-RP2 (5'-GGAAGATCTTTGTG CAATGTAACATCAGAG-3') and KAN2-FP3 (5'-GCAGGCG ATGCAAGCTTCAGGGTTG-3'). The CoPEX13 sequence is available in the DDBJ database under accession number AB507395.

\section{Genomic DNA blot analysis.}

Total DNA of $C$. orbiculare was isolated from mycelia and DNA blot analysis was performed as described previously (Takano et al. 1995). DNA digestion, gel electrophoresis, labeling of probes, and hybridization were performed according to the manufacturer's instructions and standard methods (Sambrook et al. 1989). DNA probes were labeled with digoxigenin (DIG)-dUTP using the BcaBEST DIG labeling kit (Takara, Ohtsu, Japan). Hybridized DNA was detected with antiDIG antibody Fab fragments conjugated to alkaline phosphatase (Roche Diagnostics, Tokyo) and light emission from the enzymatic dephosphorylation of CDP-Star Detection Reagent (GE Healthcare, Tokyo) was detected using the Fujifilm LAS1000 Plus Gel Documentation System.

\section{Plasmid constructs.}

The gene replacement vector pCoPEX13 $\cos 1 \mathrm{AH} 3-2$ was constructed as follows. The 2.7-kb transposon EZ::TN <KAN-2> (Epicenter), in which the kanamycin resistance gene was replaced with the ampicillin resistance gene and hygromycin resistance gene, was mixed with EZ::TN transposase (Epicenter) and

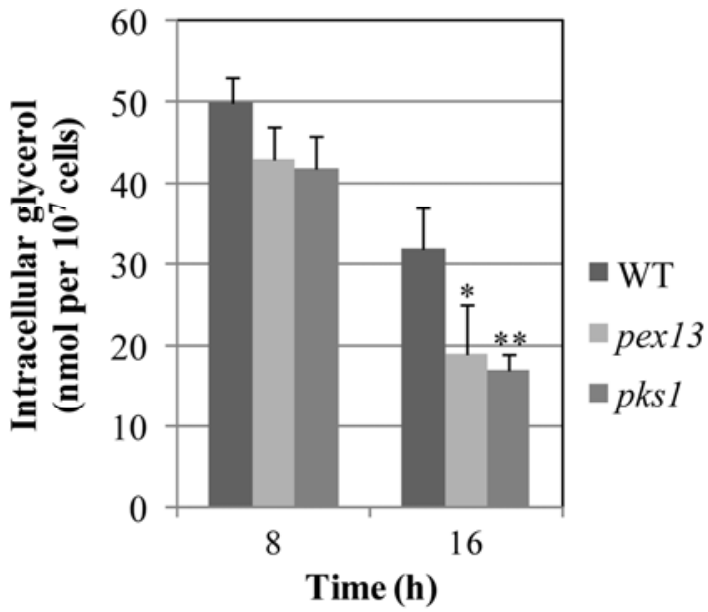

Fig. 8. Intracellular glycerol levels are affected in appressoria of the copex13 mutant. Conidia were germinated in distilled water on petri dishes at $24^{\circ} \mathrm{C}$. Concentration of intracellular glycerol in the germlings was determined at intervals using an enzymatic glycerol assay kit. Each data point represents the mean concentration determined from three independent experiments and error bars show one standard deviation. Asterisks represent significant differences between the wild type and each mutant. (Student's $t$ test: * and ** indicate $P<0.05$ and 0.001 , respectively). 
the cosmid pCoPEX13cos1. The gene complementation vector pPEX13com1 was constructed by introducing PCR-amplified CoPEX13 ORF using primer pair Pex13S1 (5'-GCAGATCTGC CGATGGAGGAAACGTTCCAT-3')/Pex13AS1 (5'-GCTCTAG ACGACATCCAAGCATTACCGAGC-3') into BamHI/XbaI digested pBIG4MRB which contains the bialaphos resistance gene (bar). The GFP-PTS1 expression construct, pEGFPPTS1, was cloned by assembling the following fragments into pBIG4MRB: a 1.5-kb fragment containing the TEF promoter and eGFP was amplified from pBIG3EGFP using primer pair TEFS1 (5'-GGACTAGTCAAACGGTGGTCAAAGGATGGG$\left.3^{\prime}\right) /$ PTS1AS1 (5'-GGCGGATCCTTACAGCTTCGACTTGTAC AGCTCGTCCAT-3') and subcloned into pBluescriptII KS(-) (pBSTEFEGFP) as a SpeI/BamHI fragment. Subsequently, the $0.2-\mathrm{kb}$ terminator region was also amplified with primer pair TermS1 (5'-GGCGGATCCACAATCAATCCATTTCGCTAT3')/GAAS1 (5'-GCGGTCGACCTGTCTGGTCTTCTACACGA A-3') and subcloned into pBSTEFEGFP (pBSGFPPTS1), as a BamHI/XhoI fragment. The GFPPTS1 was digested with SpeI/KpnI and introduced into pBIG4MRB (pEGFPPTS1). To construct the plasmid pPTS2EGFP, a $0.8-\mathrm{kb}$ TEF promoter region and a $0.9-\mathrm{kb}$ fragment containing eGFP and terminator were amplified with primer pairs TEFS1 (5'-GGACTAGTC AAACGGTGGTCAAAGGATGGG-3')/TEFGFPAS1 (5'-GGC GGATCCCATGTTTGACGGTGATGTATG-3') and GFPS 1 (5'GGACTAGTCAGACACAATGGTGAGCAAGGGCGAG-3')/ GAAS1 (5'-GCGGTCGACCTGTCTGGTCTTCTACACGAA$3^{\prime}$ ), respectively. The PTS2 signal from the FOX3 gene of $S$. cerevisiae S288C was amplified with primer pair Fox3S1 (5'GGCGGATCCTCTCAAAGACTACAAAGTA-3')/Fox3AS1 (5'-GCGAATTCACCCATGGCGCTCTCCAC-3') as a BamHI/ EcoRI fragment. These amplified fragments were subcloned into pBluescriptII KS(-) (pBSPTS2GFP). The PTS2GFP was digested with SpeI/SalI and introduced into pBIG4MRB (pPTS2EGFP).

\section{Pathogenicity tests.}

The inoculation assay on cucumber cotyledons (Cucumis sativus L. 'Suyo') was performed as described by Tsuji and associates (1997). Conidia of Colletotrichum orbiculare were obtained from 7-day-old cultures and drops $(10 \mu \mathrm{l})$ of conidial suspension $\left(5 \times 10^{5}\right.$ conidia/ml $)$ was spotted on the surface of cucumber cotyledons. To assess invasive growth ability, 10- $\mu$ d drops of spore suspension were spotted onto wound sites prepared by scratching the leaf surface with a sterile toothpick. After inoculation, the cotyledons were incubated at $24^{\circ} \mathrm{C}$ for 7 days.

\section{Light microscopy.}

For appressorium formation and penetration assays in vitro, conidia were harvested from 7-day-old PDA cultures and suspended in distilled water. The conidial suspension, adjusted to $1 \times 10^{5}$ conidia/ml, was spotted onto a multiwell glass slide (8well multitest slide; ICN Biomedicals, Aurora, OH, U.S.A.) or poured onto dialysis membranes (Wako Chemicals) and incubated in humid boxes at $24^{\circ} \mathrm{C}$. Germlings were observed with a Nikon ECLIPSE E600 microscope with differential interference contrast optics. For treatment with scytalone, conidia were germinated in a solution of $1 \mathrm{mM}$ scytalone (Kubo et al. 1996). For observing appressorium-mediated penetration, 10$\mu \mathrm{l}$ drops of conidial suspension were spotted onto the lower epidermis of cucumber cotyledons. Following incubation, the epidermal layers were peeled off using forceps, stained with lactophenol-Aniline blue, and observed by light microscopy at 3 days postinoculation. Lipid droplets in conidia and appressoria were visualized by staining with a Nile Red solution containing polyvinylpyrrolidone at $20 \mathrm{mg} / \mathrm{ml}$ and Nile Red Oxazone (Sigma-Aldrich, St. Louis) at $2.5 \mu \mathrm{g} / \mathrm{ml}$ in $50 \mathrm{mM}$ Tris-
HCl, pH 7.5 (Greenspan et al. 1985; Thines et al. 2000). Nile Red labeling was viewed by epifluorescence microscopy using the B-2A filter (450- to 490-nm excitation filter, 505-nm dichroic mirror, 520-nm barrier filter). For observation of GFP fluorescence, cells were viewed using the GFP(R)-BP filter (460- to 500-nm excitation filter, 505-nm dichroic mirror, 510to $560-\mathrm{nm}$ barrier filter).

\section{TEM.}

Samples of infected cucumber cotyledon were prepared for TEM at 3 days after inoculation as described previously (Tanaka et al. 2007). Ungerminated conidia were harvested from 7-dayold PDA cultures and immediately fixed in glutaraldehyde $(2.5 \%$ [ $\mathrm{vol} / \mathrm{vol}])$ in $0.05 \mathrm{M}$ sodium cacodylate buffer $(\mathrm{pH} 7.2)$ for $2 \mathrm{~h}$. After washing in $15 \mathrm{ml}$ of buffer, conidia were pelleted by centrifugation and mixed with an equal volume of molten low-gelling-temperature agarose (4\% [wt/vol], Sigma Product A2576). Blocks of solidified agarose containing conidia (approximately $1 \mathrm{~mm}^{3}$ ) were then post-fixed in osmium tetroxide (1\% [wt/vol]) for $2 \mathrm{~h}$, dehydrated through an ethanol series, exchanged with propylene oxide, and embedded in Spurr's epoxy resin. For infected tissue observation, pieces of cucumber cotyledon (approximately 1 by $1 \mathrm{~mm}^{2}$ ) were excised from beneath inoculation sites at 3 days after inoculation and prepared as described by Tanaka and associates (2007). Ultrathin sections were stained with uranyl acetate and lead citrate and examined with a JEM-1200EX II transmission electron microscope (JEOL, Tokyo).

\section{Glycerol assay.}

Conidia harvested from 7-day-old cultures of the wild-type strain 104-T were suspended in distilled water to a concentration of $5 \times 10^{5}$ conidia/ml. Conidial suspension $(10 \mathrm{ml})$ was poured into 9 -cm-diameter petri dishes and incubated at $24^{\circ} \mathrm{C}$. Germinated conidia were harvested by scraping them off the petri dishes with a spatula. They were then homogenized in a mortar with a pestle under liquid nitrogen. Subsequently, the debris were mixed with $5 \mathrm{ml}$ of Carrez-I-solution, $85 \mathrm{mM}$ potassium hexacyanoferrate (II) (ferrocyanide), and $5 \mathrm{ml}$ of Carrez-II-solution $(250 \mathrm{mM}$ zinc sulfate). After precipitating the cell debris by centrifugation $(1,000 \times g)$, the supernatant was analyzed using a glycerol assay kit (Boehringer, Mannheim, Germany) to estimate the intracellular glycerol concentration.

\section{ACKNOWLEDGMENTS}

This work was supported by Grants-in-Aid for Scientific Research from the Ministry of Education, Culture, Sports, Science and Technology (number 12052219, 19380029, and 21380031). R. O'Connell was supported by an Invitation Fellowship from the Japan Society for the Promotion of Science.

\section{LITERATURE CITED}

Albertini, M., Rehling, P., Erdmann, R., Girzalsky, W., Kiel, J. A., Veenhuis, M., and Kunau, W. H. 1997. Pex14p, a peroxisomal membrane protein binding both receptors of the two PTS-dependent import pathways. Cell 89:83-92.

Asakura, M., Okuno, T., and Takano, Y. 2006. Multiple contributions of peroxisomal metabolic function to fungal pathogenicity in Colletotrichum lagenarium. Appl. Environ. Microbiol. 72:6345-6354

Asakura, M. Ninomiya, S., Sugimoto, M., Oku, M., Yamashita, S., Okuno, T., Sakai, Y., and Takano, Y. 2009. Atg26-mediated pexophagy is required for host invasion by the plant pathogenic fungus Colletotrichum orbiculare. Plant Cell 21:1291-304.

Barnett, P., Bottger, G., Klein, A. T. J., Tabak, H. F., and Distel, B. 2000 The peroxisomal membrane protein Pex13p shows a novel mode of SH3 interaction. EMBO (Eur. Mol. Biol. Organ.) J. 19:6382-6391.

Bhambra, G. K., Wang, Z. Y., Soanes, D. M., Wakley, G. E., and Talbot, N. J. 2006. Peroxisomal carnitine acetyl transferase is required for elaboration of penetration hyphae during plant infection by Magnaporthe 
grisea. Mol. Microbiol. 61:46-60.

Binns, D., Januszewski, T., Chen, Y., Hill, J., Markin, V. S., Zhao, Y., Gilpin, C., Chapman, K. D., Anderson, R. G. W., and Goodman, J. M. 2006. An intimate collaboration between peroxisomes and lipid bodies. J. Cell Biol. 173:719-731.

Bundock, P., den Dulk-Ras, A., Beijersbergen, A., and Hooykaas, P. J. J. 1995. Transkingdom T-DNA transfer from Agrobacterium tumefaciens to Saccharomyces cerevisiae. EMBO (Eur. Mol. Biol. Organ.) J. 14:32063214.

Elgersma, Y., Kwast, L., Klein, A., Voorn-Brouwer, T., van den Berg, M., Metzig, B., America, T., Tabak, H. F., and Distel, B. 1996. The SH3 domain of the Saccharomyces cerevisiae peroxisomal membrane protein Pex 13p functions as a docking site for Pex $5 p$, a mobile receptor for the import PTS1-containing proteins. J. Cell Biol. 135:97-109.

Erdmann, R., and Blobel, G. 1996. Identification of Pex13p a peroxisomal membrane receptor for the PTS1 recognition factor. J. Cell Biol. 135:111-121

Fujii, I., Mori, Y., Watanabe, A., Kubo, Y., Tsuji, G.., and Ebizuka, Y. 2000. Enzymatic synthesis of 1,3,6,8-tetrahydroxynaphthalene solely from malonyl coenzyme A by a fungal iterative type I polyketide synthase PKS1. Biochemistry 39:8853-8858.

Girzalsky, W., Rehling, P., Stein, K., Kipper, J., Blank, L., Kunau, W. H., and Erdmann, R. 1999. Involvement of Pex13p in Pex14p localization and peroxisomal targeting signal 2-dependent protein import into peroxisomes. J. Cell Biol. 144:1151-1162.

Gould, S. J., Kalish, J. E., Morrell, J. C., Bjorkman, J., Urquhart, A. J., and Crane, D. I. 1996. Pex13p is an SH3 protein of the peroxisome membrane and a docking factor for the predominantly cytoplasmic PTs1 receptor. J. Cell Biol. 135:85-95.

Greenspan, P., Mayer, E. P., and Fowler. S. D. 1985. Nile red: A selective flourescent stain for intracellular lipid droplets. J. Cell Biol. 100:965-973

Heiland, I., and Erdmann, R. 2005. Biogenesis of peroxisomes: Topogenesis of the peroxisomeal membrane and matrix proteins. FEBS (Fed. Eur. Biochem. Soc.) J. 272:2362-2372.

Heinze, M., Reichelt, R., Kleff, S., and Eising, R. 2000. High resolution scanning electron microscopy of protein inclusions (cores) purified from peroxisomes of sunflower (Helianthus annuus L.) cotyledons. Cryst. Res. Technol. 35:877-886.

Howard, R. J., Ferrari, M. A., Roach, D. H., and Money, N. P. 1991. Penetration of hard substrates by a fungus employing enormous turgor pressures. Proc. Natl. Acad. Sci. U.S.A. 88:11281-11284.

Hynes, M. J., Murray, S. L., Khew, G. S., and Davis, M. A. 2008. Genetic analysis of the role of peroxisomes in the utilization of acetate and fatty acids in Aspergillus nidulans. Genetics 178:1355-1369.

Kiel, J. A. K. W., Veenhuis, M., and van der Klei, I. J. 2006. PEX Genes in fungal genomes: common, rare or redundant. Traffic 7:1291-1303.

Kim, K. W., Park, E. W., and Kim, K. S. 2004. Glyoxysomal nature of microbodies complexed with lipid globules in Botryosphaeria dothidea. Phytopathology 94:970-977.

Kimura, A., Takano, Y., Furusawa, I., and Okuno, T. 2001. Peroxisomal metabolic function is required for appressorium-mediated plant infection by Colletotrichum orbiculare. Plant Cell 13:1945-1957.

Kubo, Y., and Furusawa, I. 1991. Melanin biosynthesis: Prerequisite for successful invasion of the plant host by appressoria of Colletotrichum and Pyricularia. Pages 205-217 in: The Fungal Spore and Disease Initiation in Plants and Animals. G. T. Cole and H. C. Hoch, eds. Plenum Publishing, New York.

Kubo, Y., Takano, Y., Endo, N., Yasuda, N., Tajima, S., and Furusawa, I. 1996. Cloning and structural analysis of the melanin biosynthesis gene SCD1 encoding scytalone dehydratase in Colletotrichum lagenarium. Appl. Environ. Microbiol. 62:4340-4344.

Lichtenstein, C., and Draper, J. 1986. Genetic engineering of plants. Pages 67-119 in: DNA Cloning: A Practical Approach, Vol. 2. D. M. Glover, ed. IRL Press, Oxford.

Liu, Y. G., Mitsukawa, N., Osumi, T., and Whittier, R. F. 1995. Efficient isolation and mapping of Arabidopsis thaliana T-DNA insert junctions by thermal asymmetric interlaced PCR. Plant J. 8:457-463.

Perpetua, N. S., Kubo, Y., Yasuda, N., Takano, Y., and Furusawa, I. 1996 Cloning and characterization of a melanin biosynthetic THR1 reductase gene essential for appressorial penetration of Colletotrichum lagenerium. Mol. Plant-Microbe Interact. 9:323-329.

Ramos-Pamplona, M., and Naqvi, N.I. 2006. Host invasion during riceblast disease requires carnitine-dependent transport of peroxisomal acetyl-CoA. Mol. Microbiol. 61:61-75.

Sambrook, J., Fritsch, E. F., and Maniatis, T. 1989. Molecular Cloning: A Laboratory Manual. Cold Spring Harbor Laboratory Press, Cold Spring Harbor, NY, U.S.A.

Schadeck, R. J. G., Leite, B., and de Freitas Buchi, D. 1998. Lipid mobili- zation and acid phosphatase activity in lytic compartments during conidium dormancy and appressorium formation of Colletotrichum lagenarium. Cell Struct. Funct. 23:333-340.

Stein, K., Schell-Steven, A., Erdmann, R., and Rottensteiner, H. 2002. Interactions of Pex $7 \mathrm{p}$ and Pex 18p/Pex $21 \mathrm{p}$ with the peroxisomal docking machinery: implications for the first steps in PTS2 protein import. Mol. Biol. Cell 22:6056-6069.

Subramani, S. 1993. Protein import into peroxisomes and biogenesis of the organelle. Annu. Rev. Cell Biol. 9:445-478.

Subramani, S., Koller, A., and Snyder, W. B. 2000. Import of peroxisomal matrix and membrane proteins. Annu. Rev. Biochem. 69:399-418.

Swinkels, B. W., Gould, S. J., Bodner, A. G., Rachubinski, R. A., and Subramani, S. 1991. A novel, cleavable peroxisomal targeting signal at the amino-terminus of the rat 3-ketoacyl-CoA thiolase. EMBO (Eur Mol. Biol. Organ.) J. 10:3255-3262.

Takano, Y., Kubo, Y., Shimizu, K., Mise, K., Okuno, T., and Furusawa, I. 1995. Structural analysis of $P K S 1$, a polyketide synthase gene involved in melanin biosynthesis in Colletotrichum lagenarium. Mol. Gen. Genet. 249:162-167.

Tanaka, S., Yamada, K., Yabumoto, K., Fujii, S., Huser, A., Tsuji, G., Koga, H., Dohi, K., Mori, M., Shiraishi, T., O'Connell, R., and Kubo Y. 2007. Saccharomyces cerevisiae SSD1 orthologues are essential for host infection by the ascomycete plant pathogens Colletotrichum lagenarium and Magnaporthe grisea. Mol. Microbiol. 64:1332-1349.

Thines, E., Weber, R. W., and Talbot, N. J. 2000. MAP kinase and protein kinaseA-dependent mobilization of triacylglycerol and glycogen during appressorium turgor generation by Magnaporthe grisea. Plant Cell 12:1703-1718

Titorenko, V. I., and Rachubinski, R. A. 2001. Dynamics of peroxisome assembly and function. Trends Cell. Biol. 11:22-29.

Titorenko, V. I., and Rachubinski, R. A. 2004. The peroxisome: orchestrating important developmental decisions from inside the cell. J. Cell Biol. 164:641-645

Tsuji, G., Takeda, T., Furusawa, I., Horino, O., and Kubo, Y. 1997. Carpropamid, an anti-rice blast fungicide, inhibits scytalone dehydratase activity and appressorial penetration in Colletotrichum lagenarium. Pestic. Biochem. Physiol. 57:211-219

Tsuji, G., Kenmochi, Y., Takano, Y., Sweigard, J., Farrall, L., Furusawa, I., Horino, O., and Kubo, Y. 2000. Novel fungal transcriptional activator, Cmrlp of Colletotrichum lagenarium and Pig1p of Magnaporthe grisea, contain Cys2His2 zinc finger and Zn(II)2Cys6 binuclear cluster DNA binding motifs, and regulate transcription of melanin biosynthesis genes in a development specific manner. Mol. Microbiol. 38:940-954.

Tsuji, G., Fujii, S., Fujihara, N., Hirose, C., Tsuge, S., Shiraishi, T., and Kubo, Y. 2003. Agrobacterium tumefaciens-mediated transformation for random insertional mutagenesis in Colletotrichum lagenarium. J. Gen. Plant. Pathol. 69:230-239.

Van Dyke, C. G., and Mims, C. W. 1991. Ultrastructure of conidia, conidium germination, and appressorium development in the plant pathogenic fungus Colletotrichum truncatum. Can. J. Bot. 69:2455-2467.

Veenhuis, M., Keizer, I., and Harder, W. 1979. Characterization of peroxisomes in glucose-grown Hansenula polymorpha and their development after the transfer of cells into methanol-containing media. Arch. Microbiol. 120:167-175.

Wanders, R. J. A., and Waterman, H. R. 2004. Peroxisomal disorders I: biochemistry and genetics of peroxisome biogenesis disorder. Clin. Genet. 67:107-133

Wang, Z. Y., Thornton, C. R., Kershaw, M. J., Debao, L., and Talbot, N. J. 2003. The glyoxylate cycle is required for temporal regulation of virulence by the plant pathogenic fungus Magnaporthe grisea. Mol. Microbiol. 47:1601-1612.

Wang, Z. Y., Jenkinson, J. M., Holcombe, L. J., Soanes, D. M., VeneaultFourrey, C., Bhambra, G. K., and Talbot, N. J. 2005. The molecular biology of appressorium turgor generation by the rice blast fungus Magnaporthe grisea. Biochem. Soc. Trans. 33:384-388.

Wang, Z. Y., Soanes, D. M., Kershaw, M. J., and Talbot, N. J. 2007. Functional analysis of lipid metabolism in Magnaporthe grisea reveals a requirement for peroxisomal fatty acid $\beta$-oxidation during appressorium-mediated plant infection. Mol. Plant-Microbe Interact. 20:475-491.

Weber, R. W. S., Wakley, G. E., Thines, E., and Talbot, N. J. 2001. The vacuole as central element of the lytic system and sink for lipid droplets in maturing appressoria of Magnaporthe grisea. Protoplasma 216:101-112.

\section{AUTHOR-RECOMMENDED INTERNET RESOURCE}

National Center for Biotechnology Information BLAST webpage: www.ncbi.nlm.nih.gov/BLAST 